\title{
Asexual Propagation of Eggplant (Solanum melongena L.) through Encapsulated Axillary Buds
}

\author{
A.K.M. N. Huda ${ }^{1}$, M.A. Bari ${ }^{2}$ and M. Rahman* \\ Deptartment of Genetic Engineering \& Biotechnology, University of Rajshahi, \\ Rajshahi-6205, Bangladesh \\ Key words: Auxillary buds, Eggplant, Encapsulation, Synthetic seed
}

Axillary buds from two varieties of Solanum melongina L., namely Loda and China were encapsulated in sodium alginate to produce artificial seed. These artificial seeds can be stored at $4^{\circ} \mathrm{C}$ for 45 days in a glass vessel. Best germination of these artificial seeds was obtained on MS0 containing $0.5 \mathrm{mg} / \mathrm{l} \mathrm{BAP}$ with 0.1 $\mathrm{mg} / \mathrm{l} \mathrm{GA}$. In this medium 94 and $90 \%$ of the synthetic seeds were found to germinate and produce shoots in case of Loda and China respectively within four - six days of culture on MS0.

The eggplant (Solanum melongena L.), a member of Solanaceae, is cultivated as a vegetable crop throughout the tropics and as summer annual in the subtropics. It is highly productive and usually considered as the "poor man's crop" (Chowdhury 1966), which is an important item of diet consumed in a great variety of ways. The eggplant contains food values (Bose et al. 1993) because its edible portion contains considerable amount of protein, carbohydrate, fat, minerals and vitamins. In addition to its food values the eggplant is also used for medicinal purposes. Kirtikar and Basu (1933) have mentioned its use in "Ayurveda" as appetizer, aphroisiac, cardiotonic and other purposes.

Eggplant is a highly productive vegetable and can be cultivated in natural environment of Bangladesh without much care. Its cultivation is usually suffered by some bacterial, virus and mainly by insect pests. The fruit fly (Leucinodes orbonalis), an insect which damage up to $30 \%$ of total yield (Shukla and Upadhyay 2000). Insect borer and viral infection are the main problems in eggplant and leads to develop disease resistance and high yielding variety. But in this case, maintenance of developed genotypes (e.g. hybrid, meiotically unstable genotypes, and genetically engineered genotypes) may be a great problem for its propagation. True type production can easily be practiced in

*Author for Correspondence.<motiur7@yahoo.com>. ${ }^{1}$ Department of Biotechnology \& Genetic Engineering, Islamic University, Kushtia, Bangladesh. ${ }^{2}$ Institute of Biological Sciences, University of Rajshahi, Rajshahi-6205, Bangladesh. 
asexual means which is absolutely lacking in eggplant. Artificial seed production, encapsulating the vegetative bud, is an important alternative to overcome the above mentioned problem (maintenance of developed genotypes). Synthetic seeds, by artificial means, are also important for the purpose of scientific conservation of the genotypes.

Two varieties of Solanum melongena, namely Loda and China were used. Seeds of these two varieties were cultured on MS for seedlings. Axillary buds were collected after four weeks of seedling initiation. Buds with nodal segment were used as explants.

Sodium alginate was added in MS containing phytohormone and mixed well for making it a homogenous solution. The explants dipped into the alginate solution were taken up by a pair of forceps and placed to the beaker of $\mathrm{CaCl}_{2}$ and individual explant was encoated with alginate.

To examine the germination rate, synthetic seeds were cultured on MS and data were recorded. On the other hand, to examine the viability of synthetic seeds, they were stored at 4 and $0^{\circ} \mathrm{C}$ in refrigerator for 15, 30, 45, 60, 90 and 120 days. After storage, seeds were brought out from the refrigerator and cultured on MS0 medium.

To establish a suitable medium composition of artificial seed, different concentrations and combinations of phytohormones were added to synthetic seed bead along with MS. For this purposes, BAP and $\mathrm{Kn}$ alone and in combination with NAA, IBA and GA3 were used in artificial seed bead medium (Fig. A). Data were taken on germination percentage, days to germination and shoot length (Table 1).

Best result was obtained when $0.5 \mathrm{mg} / 1 \mathrm{BAP}$ with $0.1 \mathrm{mg} / \mathrm{l} \mathrm{GA} 3$ were used in seed bead (Fig. B, C). In this combination 94 and $90 \%$ synthetic seeds of Loda and China variety, respectively germinated within four to six days of culture on MS0. Second highest germination rate was observed in seed bead supplemented with $1.0 \mathrm{mg} / \mathrm{l} \mathrm{BAP}+0.1 \mathrm{mg} / \mathrm{l} \mathrm{GA}$. In this combination $87 \%$ seeds of Loda variety germinated within three to four days of culture as against $85 \%$ seeds of China variety within four to five days of culture. But when only MS0 was used without any growth regulator, seeds failed to germinate.

The influence of storage at 0 and $4^{\circ} \mathrm{C}$ on germination rate of synthetic seed was also examined. The seeds were kept in a glass vessel and then stored at 0 and $4^{\circ} \mathrm{C}$ for $15,30,45,60,90$ and 120 days. The result indicated that seeds can be stored at $4^{\circ} \mathrm{C}$ for 45 days. But seeds could not be stored at $0^{\circ} \mathrm{C}$ because at this temperature explants underwent crystal formation due to lack of cryoprotectant. Roots were induced from germinated seedlings within 30 - 35 days without being treated in rooting medium. Nodal segments containing auxillary bud of 
two varieties (Loda and China) were used as explants for artificial seed production although most of studies on encapsulation carried out using somatic embryo as the encapsulating propagules (Radenbaugh et al. 1986). There are some reports, in addition to using somatic embryos, auxillary buds, shoot tips have also been used in the preparation of synthetic seeds (Redenbaugh 1993, Bapat and Rao 1988, 1990, Ganapathia et al. 1992, 1994). In some studies use of meristematic shoot tips or axillary buds for the production of synthetic seed as reported for banana (Ganapathia et al. 1992, 1998), mulberry (Bapat et al. 1987, Niino et al. 1992), horseradish (Uozumi et al.1994) and apple, kiwifruit, black berry (Piccioni and Standardi 1995). Among the different encapsulating agent, sodium alginate was used due to it's solubility at room temperature and ability to form completely permeable gell with calcium chloride (Bapat et al. 1987). It was found in carrot or celery, that a suitable synthetic endosperm required
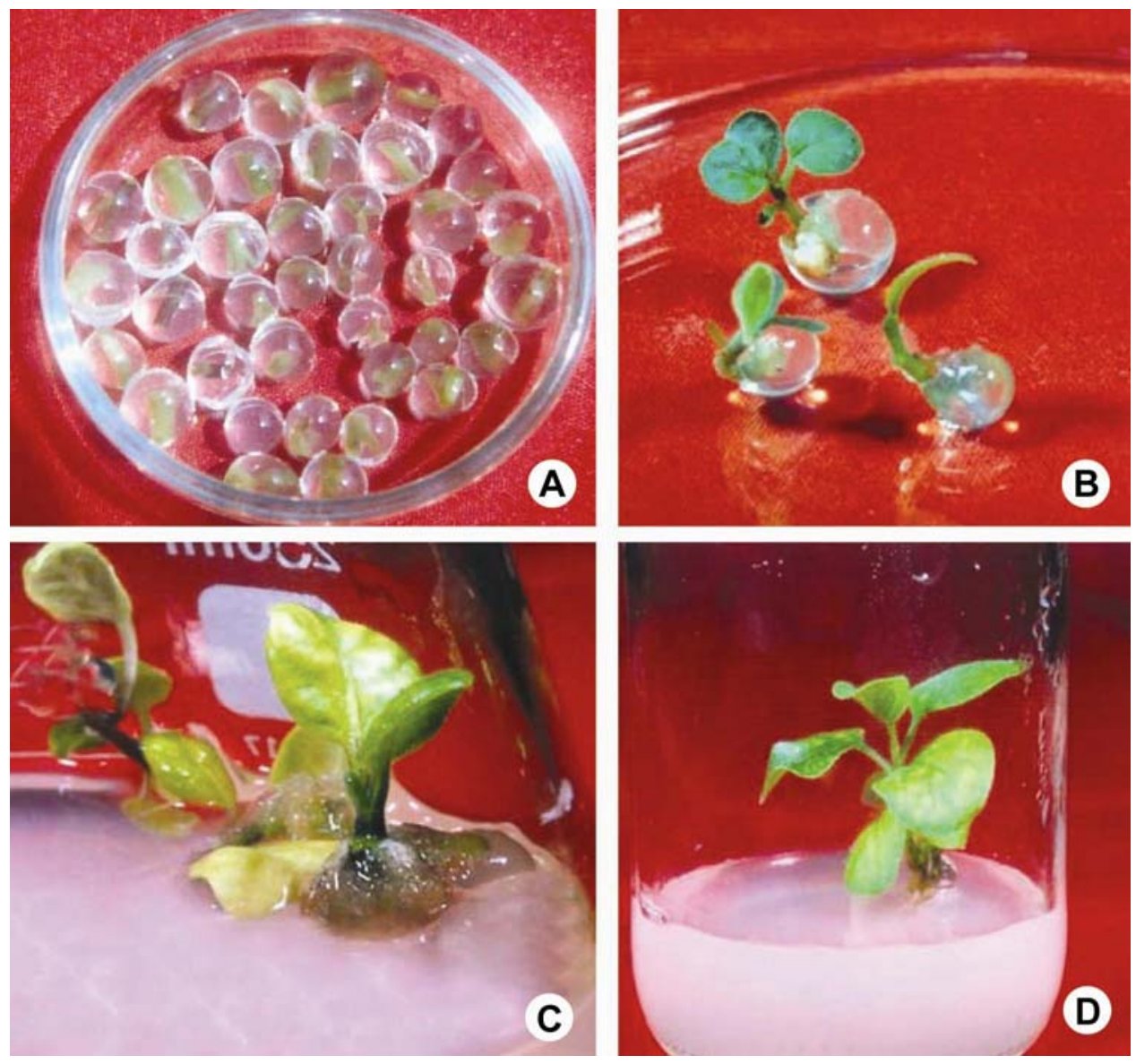

Fig. 1. Different stages of synthetic seed germination: A. Encapsulated nodal segments, B-C. Germinated synthetic seeds. D. Growing plantlet obtained from synthetic seed. 
Table 1. Effect of growth regulators on artificial seed germination. Shoot length was recorded after four weeks of culture.

\begin{tabular}{|c|c|c|c|c|c|c|c|}
\hline \multicolumn{2}{|c|}{ Growth regulators } & \multicolumn{6}{|c|}{ Eggplant varieties } \\
\hline \multirow{2}{*}{$\begin{array}{l}\text { Combi- } \\
\text { nation }\end{array}$} & \multirow{2}{*}{$\begin{array}{l}\text { Concen- } \\
\text { tration } \\
(\mathrm{mg} / \mathrm{l})\end{array}$} & \multicolumn{3}{|c|}{ Loda } & \multicolumn{3}{|c|}{ China } \\
\hline & & $\begin{array}{l}\text { Days to } \\
\text { germina- } \\
\text { tion }\end{array}$ & $\begin{array}{c}\text { Germina- } \\
\text { tion (\%) }\end{array}$ & $\begin{array}{l}\text { Shoot length } \\
\qquad(\mathrm{cm}) \\
(\bar{X} \pm \text { S.E })\end{array}$ & $\begin{array}{l}\text { Days to } \\
\text { germina- } \\
\text { tion }\end{array}$ & $\begin{array}{l}\text { Germi- } \\
\text { nation } \\
(\%)\end{array}$ & $\begin{array}{l}\text { Shoot length } \\
\qquad(\mathrm{cm}) \\
(\bar{X} \pm \text { S.E })\end{array}$ \\
\hline Control & MS0 & - & - & - & - & - & - \\
\hline \multirow{4}{*}{ BAP } & 0.10 & $7-10$ & 55 & $1.0 \pm 0.1$ & $9-12$ & 52 & $0.9 \pm 0.1$ \\
\hline & 0.50 & $5-7$ & 60 & $1.9 \pm 0.3$ & $6-7$ & 59 & $1.5 \pm 0.2$ \\
\hline & 1.00 & $3-5$ & 55 & $2.5 \pm 0.5$ & $4-6$ & 54 & $2.1 \pm 0.6$ \\
\hline & 1.50 & - & - & - & - & - & - \\
\hline \multirow{6}{*}{$\mathrm{BAP}+\mathrm{NAA}$} & $0.5+0.01$ & $4-5$ & 68 & $1.6 \pm 0.1$ & $5-6$ & 62 & $1.4 \pm 0.3$ \\
\hline & $0.5+0.05$ & $5-7$ & 65 & $2.3 \pm 0.3$ & $5-9$ & 58 & $2.1 \pm 0.2$ \\
\hline & $0.5+0.10$ & $5-7$ & 65 & $2.5 \pm 0.3$ & $5-7$ & 60 & $2.1 \pm 0.4$ \\
\hline & $1.0+0.01$ & $3-5$ & 80 & $2.7 \pm 0.5$ & $3-6$ & 71 & $2.5 \pm 0.4$ \\
\hline & $1.0+0.05$ & $3-4$ & 80 & $2.6 \pm 0.3$ & $3-6$ & 75 & $2.5 \pm 0.6$ \\
\hline & $1.0+0.10$ & $3-4$ & 57 & $2.1 \pm 0.1$ & $3-5$ & 59 & $2.0 \pm 0.01$ \\
\hline \multirow{6}{*}{$\mathrm{BAP}+\mathrm{IBA}$} & $0.5+0.01$ & $5-6$ & 70 & $1.8 \pm 0.3$ & $5-7$ & 68 & $1.6 \pm 0.4$ \\
\hline & $0.5+0.05$ & $4-7$ & 78 & $1.9 \pm 0.2$ & $5-8$ & 72 & $1.9 \pm 0.3$ \\
\hline & $0.5+0.10$ & $4-7$ & 76 & $1.8 \pm 0.5$ & $4-7$ & 72 & $1.8 \pm 0.3$ \\
\hline & $1.0+0.01$ & $3-5$ & 80 & $2.0 \pm 0.1$ & $3-5$ & 73 & $2.0 \pm 0.2$ \\
\hline & $1.0+0.05$ & $3-6$ & 80 & $2.1 \pm 0.1$ & $3-5$ & 75 & $2.0 \pm 0.3$ \\
\hline & $1.0+0.10$ & $5-7$ & 60 & $1.9 \pm 0.5$ & $3-5$ & 56 & $1.8 \pm 0.3$ \\
\hline \multirow{3}{*}{$\mathrm{Kn}$} & 0.1 & $4-7$ & 50 & $2.0 \pm 0.3$ & $5-7$ & 46 & $1.9 \pm 0.2$ \\
\hline & 0.5 & $3-5$ & 55 & $1.6 \pm 0.1$ & $3-7$ & 49 & $1.5 \pm 0.3$ \\
\hline & 1.0 & $4-8$ & 80 & $1.3 \pm 0.6$ & $4-6$ & 76 & $1.2 \pm 0.5$ \\
\hline \multirow{6}{*}{$\mathrm{Kn}+\mathrm{NAA}$} & $0.5+0.01$ & $4-9$ & 82 & $2.5 \pm 0.6$ & $4-9$ & 70 & $2.5 \pm 0.01$ \\
\hline & $0.5+0.05$ & $3-6$ & 82 & $3.0 \pm 0.7$ & $4-7$ & 83 & $2.9 \pm 0.8$ \\
\hline & $0.5+0.10$ & $3-5$ & 84 & $3.1 \pm 0.1$ & $3-6$ & 81 & $3.0 \pm 0.2$ \\
\hline & $1.0+0.01$ & $4-6$ & 80 & $2.7 \pm 0.3$ & $4-6$ & 78 & $2.8 \pm 0.4$ \\
\hline & $1.0+0.05$ & $3-7$ & 75 & $2.7 \pm 0.3$ & $4-6$ & 70 & $2.7 \pm 0.1$ \\
\hline & $1.0+0.10$ & $3-6$ & 70 & $2.9 \pm 0.1$ & $3-7$ & 60 & $2.6 \pm 0.3$ \\
\hline \multirow{6}{*}{$\mathrm{Kn}+\mathrm{IBA}$} & $0.5+0.01$ & $3-7$ & 70 & $1.6 \pm 0.2$ & $3-6$ & 69 & $1.5 \pm 0.3$ \\
\hline & $0.5+0.05$ & $3-6$ & 75 & $1.4 \pm 0.3$ & $3-8$ & 70 & $1.3 \pm 0.6$ \\
\hline & $0.5+0.10$ & $3-6$ & 70 & $1.3 \pm 0.6$ & $3-7$ & 69 & $1.0 \pm 0.2$ \\
\hline & $1.0+0.01$ & $3-7$ & 80 & $2.7 \pm 0.1$ & $3-8$ & 77 & $2.5 \pm 0.4$ \\
\hline & $1.0+0.05$ & $4-7$ & 75 & $3.0 \pm 0.1$ & $3-8$ & 69 & $2.9 \pm 0.6$ \\
\hline & $1.0+0.10$ & $3-6$ & 50 & $3.5 \pm 0.2$ & $3-7$ & 45 & $3.4 \pm 0.6$ \\
\hline \multirow{3}{*}{$\mathrm{GA}_{3}$} & 0.1 & $5-7$ & 65 & $2.0 \pm 0.1$ & $6-7$ & 60 & $1.7 \pm 0.3$ \\
\hline & 0.5 & $4-6$ & 81 & $2.1 \pm 0.1$ & $4-6$ & 75 & $1.9 \pm 0.3$ \\
\hline & 1.0 & $4-6$ & 85 & $2.5 \pm 0.3$ & $4-6$ & 80 & $2.0 \pm 0.1$ \\
\hline \multirow{2}{*}{$\mathrm{GA}_{3}+\mathrm{BAP}$} & $0.1+0.5$ & $4-6$ & 94 & $2.0 \pm 0.3$ & $4-6$ & 90 & $1.8 \pm 0.1$ \\
\hline & $0.1+1.0$ & $3-4$ & 87 & $2.9 \pm 0.4$ & $4-5$ & 85 & $2.5 \pm 0.2$ \\
\hline $\mathrm{GA}_{3}+\mathrm{Kn}$ & $0.1+0.1$ & $4-5$ & 86 & $2.5 \pm 0.8$ & $4-6$ & 81 & $2.5 \pm 0.1$ \\
\hline
\end{tabular}


in the seed bead medium. Machii (1992) achieved optimum germination rate of synthetic seed in Morus alba using BAP alone in seed bead medium. On the other hand, in Cleopatra tangerine, best germination was observed using $1.0 \mu \mathrm{M} / 1 \mathrm{GA} 3$ $\mathrm{GA}_{3}$ in seed bead, whereas zygotic embryos were used as explant in synthetic seed to standardize an artificial endosperm for synthetic seed production using somatic embryos (Nadina et al. 1998). But in this experiment, BAP and GA3 combination gave optimum germination than BAP alone. Besides this, Soneji et al. (2002) used hormone free seed bead medium in pineapple and failed to obtain germination. The present investigation indicated that like pineapple, eggplant also requires hormones (BAP, $\mathrm{Kn}$ and $\mathrm{GA}_{3}$ ) in seed bead medium for germination.

A significant observation in this study was that the encapsulated buds did not lose the capacity for germination even after storing at $4^{\circ} \mathrm{C}$ for 45 days. Similar result was also observed in mulberry (Bapat et al. 1987) and Japanese White Birch (Kinoshita and Saito 1990).

Under the present investigation effort was made to develop the protocol for formation and production of artificial seeds of Loda and China varieties of eggplants. The result demonstrated that seeds can be germinated on MS0 or even on agar beds containing distilled water, which reduced the labour and cost. In eggplants propagation by synthetic seeds would initiate asexual means to a new area of advanced research for developing the conservation strategies for eggplant genetic resources through chilling and cryopreservation.

\section{References}

Bapat VA, Mhatre M and Rao PS (1987) Propagation of Morus indica L. (Mulberry) by encapsulated shoot buds. Plant Cell Reports 6: 393-395.

Bapat VA and Rao PS (1988) Sandal wood plantlets from synthetic seeds. Plant Cell Reports 7: 434-436.

Bapat VA and Rao PS (1990) In vitro growth of encapsulated auxillary buds of mulberry (Morus indica L.) Plant Cell Tiss. Org. Cult. 20:69-70.

Bose TK, Some MG and Kabir K (1993) Vegetable crops (2 $2^{\text {nd }}$ ed.). Noya Prokash, Kalyani, India, pp. 281.

Chowdhury B (1966) Eggplant (Solanum melongena). In: Evaluation of crop plants. N.W. Simmonds (Ed). Longman Pub. Great Britain pp. 278-279.

Ganapathia TR, Bapat VA and Rao PS (1994) In vitro development of encapsulated shoot tips of cardamon. Biotech. Techniques 8(4): 239-244.

Ganapathi TR, Kulkarni VM, Suprasanna P, Bapat VA and Rao PS (1998) Studies on in vitro multiplication and encapsulation in an elite variety of banana-Lal Kela (AAA). Proc. Natle. Acad. Sci. USA 68B: 45-51. 
Ganapathia TR, Suprasanna P, Bapat VA and Rao PS (1992) Propagation of banana through encapsulated shoot tips. Plant Cell Reports 11: 571-575.

Kinoshita Isao and Akira Saito (1990) Propagation of Japanese white birch by encapsulated axillary buds. J. Jpn. For. Soc. 72(2): 166-170.

Kirtikar KR and Basu BD (1933) Indian medicinal plants, 3: 1757-1759.

Machii Hiroaki (1992) In vitro growth of encapsulated adventitious buds in Mulberry, Morus alba L. Japan. J. Breed. 42: 553-559.

Nadina Nieves, Jose C, Lorenzo Maria de los A, Blanco, Justo Gonzaley, Hiplito Peralta, Mortha Hernandezy, Raon Santos, Oscar Concepcion, Carlos G Borroto, Eduviges Borroto, Raul Tapia, Marcos E, Mastinez, Zadia Fundora and Alfredo Gonzaley (1998) Artificial endosperm of Cleopatra tangerine zygotic embryos: a model for somatic embryo encapsulation. Plant Cell, Tiss. Org. Cult. 54: 77-83.

Niino T, Sakai A and Yakuwa H (1992) Cryopreservation of dried shoot tips of mulberry winter buds and subsequent plant regeneration. Cryobiol Lett. 13: 51-58.

Piccioni E and Standardi A (1995). Encapsulation of micropropagated buds of six woody species. Plant Cell Tissue Organ Cult. 42: 221-226.

Radenbaugh K (1993) Syn. Seed: Applications of synthetic seeds to crop improvement. CRC Press. Boca Raton, U.S.A.

Redenbaugh K, Fuji J and Slade D (1988) Encapsulated Plant Embryos in: Mizrahi, A. (Ed.). Biotechnology in agriculture. AR Liss. New York. pp. 225-248.

Redenbaugh K, Paasch BD, Nichol JW, Kossler ME, Viss PR and Walker KA (1986) Somatic Seeds: Encapsulation of asexual embryos. Biotech. 4: 797-801.

Shukla GS and Upadhyay VB (2000) Economic Zoology (4th edt.). Rastogi Publication, Gangotri Shivaji road, India. pp. 121-123.

Soneji JR, Rao PS and Mhatre M (2002) Germination of synthetic seeds of pineapple (Ananas comosus L. Merr.) Plant Cell Repot. DOI 10-1007/s 00299-011-0417-9.

Uozumi N, Asano Y and Kobayashi T (1994) Micropropagation of horseradish hairy root by means of adventitious shoot primordia. Plant Cell Tiss. Org. Cult. 36: 183-190. 